\title{
Acute appendicitis: a 2- year review of clinical presentation and histopathology
}

\author{
Subedi $\mathrm{N}^{1}$, Dangol US ${ }^{1}$, Adhikary $\mathrm{MB}^{1}$, Pudasaini $\mathrm{S}^{2}$, Baral R ${ }^{2}$ \\ ${ }^{1}$ Department of Surgery, Helping hands community hospital, Kathmandu, Nepal \\ ${ }^{2}$ Department of Pathology, Helping hands community hospital, Kathmandu, Nepal
}

\author{
Keywords: \\ Acute appendicitis; \\ Appendectomy; \\ Appendicular perforation; \\ Histopathology
}

\begin{abstract}
Background: Acute appendicitis is the most common surgical emergency. Obstruction of the lumen by fecolith is the usual cause of acute appendicitis. The aim of the study was to analyze clinical presentation of acute appendicitis and its histopathological correlation.
\end{abstract}

Materials and Methods: A retrospective study of acute appendicitis was done in the Department of Surgery of Helping Hands Community Hospital from January 2009 to December 2010. Three hundred forty five patients out of 415 patients with clinical diagnosis of appendicitis underwent operative treatment. The histopathological reports were reviewed and correlated with clinical diagnosis.

Results: Out of 345 patients who underwent operative procedure $98 \%(n=338)$ came with chief complaint of pain in the periumbilical region migrating to the right iliac fossa. The mean age of presentation was 42 years. Increased leucocyte count was seen in only $65 \%$ cases. Acute appendicitis was more commonly seen in male patients (214 cases, $62 \%)$. The most common per operative finding was acutely inflammed appendix (84\%) followed by perforated appendix $(7.5 \%)$, gangrenous appendix $(3.5 \%)$ and appendicular lump (1.5\%). However, histopathological diagnoses were acute appendicitis (91.9\%), resolving appendicitis $(3.5 \%)$, lymphoid hyperplasia $(2.6 \%)$, mucocele $(0.3 \%)$ and carcinoid $(0.3 \%)$. Normal histology was seen in $1.4 \%$ cases.

\section{Conclusion:}

Though there are other causes of acute abdomen, acute appendicitis still stands first amongst all the emergencies. Histopathological examination of appendectomy specimen should not be omitted in order to see the incidence negative appendectomy rate and to avoid complications relating to malignant conditions.

\section{INTRODUCTION}

Acute appendicitis is the most common acute surgical condition of the abdomen. ${ }^{1-4}$ Obstruction of the lumen is the dominant factor for acute appendicitis and fecoliths are

\section{Correspondence:}

Dr. Neeraj Subedi, MS

Department of Surgery, Nepal Medical College Teaching Hospital, Kathmandu, Nepal

E-mail:neerajsubedi@yahoo.com the usual cause of obstruction. Other causes of obstruction could be lymphoid hyperplasia, intestinal worms, tumors, or other conditions. ${ }^{2}$

Accurate preoperative diagnosis is always not possible. Delay in the treatment can cause certain complications. On the other hand, prompt diagnosis and early operation can result in a number of negative appendectomies. ${ }^{3}$ Many surgeons will accept a certain rate of negative laparotomy 
in order to avoid missing an inflammed appendix and its complications like perforation. ${ }^{5}$

This study was carried out to analyze the clinical presentation, rate of negative appendectomy and histopathological correlation.

\section{MATERIALS AND METHODS}

A retrospective study of acute appendicitis was done in the Department of Surgery of Helping Hands Community Hospital during two years period (January 2009 to December 2010). There were a total of 415 patients with clinical diagnosis of appendicitis were admitted during the period. Out of these, 345 patients underwent operative treatment.

Detailed clinical history of the patient was recorded from the patient's file. The different parameters like age, gender, clinical features, lab investigations and operative findings were analyzed. The histopathological reports were reviewed and correlated with clinical diagnosis. Statistical analysis was done by SPSS 10 for windows.

\section{RESULTS}

Out of 415 cases of clinical diagnosis of acute appendicitis, 345 patients underwent appendectomy. The age range was from 7 years to 77 years with mean age of presentation of 42 years. The youngest patient was 7 years old and the oldest patient was 77 years old.

Chief complaint of the patient was pain in the periumbilical region migrating to the right iliac fossa. Increased leucocyte count was seen in $74 \%$ cases with neutrophilia in $65 \%$ cases. Acute appendicitis was more commonly seen in male patients ( 214 cases, $62 \%$ ) than females (131 cases, 38\%).

The results of operative findings are tabulated in Table 1 .

Histopathological reports are tabulated in Table 2.

\section{DISCUSSION}

The diagnosis of acute appendicitis remains mostly on the basis of clinical manifestation. ${ }^{4}$

Being the most common problem requiring emergency surgery, the accuracy of the clinical diagnosis has been estimated between $76 \%$ and $92 \%$ because of which accurate diagnosis of acute appendicitis is still difficult. However delay in diagnosis leads to increased rates of morbidity and mortality. On the other hand, the negative rate of appendectomy varies from 15 to $30 \% .^{1}$ The problem in making a clinical diagnosis of appendicitis is because of other possible surgical and nonsurgical causes of lower abdominal pain. ${ }^{4}$
In this study, age of the patient ranged from 7 to 77 years. Similar findings were observed in other studies. ${ }^{2,6,7}$ Our study showed that acute appendicitis was more commonly seen in male patients (220 cases, 63.8\%). Similar finding was reported in other literature..$^{1-4,6-8}$

The characteristic abdominal pain starting at periumbilical region and migrating to right iliac fossa with increased neutrophil count has been considered to be a useful finding in the diagnosis of acute appendicitis. This is seen in $65 \%$ cases in our study which showed concordance with other studies. ${ }^{1,4,9}$

In our study, appendectomies with histological feature of acute appendicitis were observed in $91.9 \%$ cases. Many other studies confirmed the clinical diagnosis of acute appendicitis which correlated well with histopathological study., $3,4,6,8,10$ Perforated appendix was seen in 26 cases (7.5\%). Other studies showed similar rate of perforation. ${ }^{11-13}$ However studies done by Nabipour et $\mathrm{al}^{6}$ and Makaju et al showed lower rate of perforated appendicitis as $0.8 \%$ and $2.12 \%$ respectively. ${ }^{6,14}$

Gangrenous appendicitis was seen in $3.5 \%$ cases in our study which was lower than the rate seen in a study done in Kerman- Iran, where the rate was $8 \% .{ }^{6}$ Eshy et $\mathrm{al}^{5}$ found $0.7 \%$ of gangrenous appendicitis in their series. In another study done in Nepal, $16.99 \%$ cases were of gangrenous

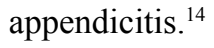

Appendicular lump is a common complication of acute appendicitis who have been treated conservatively. Appendicular lump was seen in $1.5 \%$ cases in our study.

Table 1: Operative findings

\begin{tabular}{lc}
\hline Per operative findings & No. of cases (\%) \\
\hline Acutely inflamed appendix & $290(84 \%)$ \\
\hline Perforated appendix & $26(7.5 \%)$ \\
\hline Gangrenous appendix & $12(3.5 \%)$ \\
\hline Appendicular mass & $5(1.5 \%)$ \\
\hline Normal looking appendix & $12(3.5 \%)$ \\
\hline Total & $\mathbf{3 4 5}$ \\
\hline
\end{tabular}

Table 2: Histopathological findings

\begin{tabular}{lc}
\hline Histopathological diagnosis & No of cases (\%) \\
\hline Acute appendicitis & $317(91.9 \%)$ \\
\hline Resolving appendicitis & $12(3.5 \%)$ \\
\hline Lymphoid hyperplasia & $9(2.6 \%)$ \\
\hline Normal appendix & $5(1.4 \%)$ \\
\hline Mucocele & $1(0.3 \%)$ \\
\hline Carcinoid tumor & $1(0.3 \%)$ \\
\hline Total & $\mathbf{3 4 5 ( 1 0 0 \%}$ \\
\hline
\end{tabular}




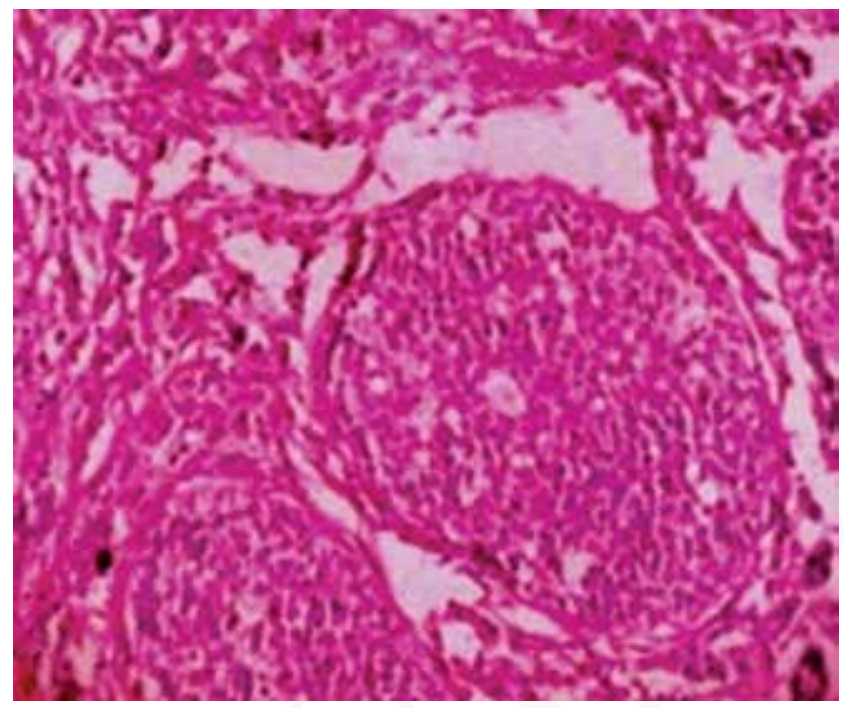

Figure 1: Photomicrograph showing tumor cells arranged in nest (HE stain, X20)

In contrast to our study, $\mathrm{Al}$ samarrai et a $\mathrm{l}^{15}$ showed $18.4 \%$ cases of appendicular mass diagnosed clinically in his study. Dominquez et $\mathrm{al}^{16}$ showed $6.49 \%$ of appendicular mass.

Resolving appendicitis was seen in $3.5 \%$ cases in our study. $7.9 \%$ and $6.5 \%$ was seen in studies done by Ojo et al and Barber et al respectively. ${ }^{10,17}$ Likewise, lymphoid hyperplasia was seen in $2.6 \%$ cases. However in a study done by Khan et al, lymphoid hyperplasia was seen in $0.2 \%$ cases. $^{8}$ In contrast, $16.1 \%$ cases of lymphoid hyperplasia was seen in a study done by Malloy et a ${ }^{18}$ study has shown that lymphoid hyperplasia is frequently the precursor of acute appendicitis. ${ }^{19}$

Histopathological examination showed $1.4 \%$ cases of normal appendix in our study. But in aother study, the rate of normal appendectomy was $14.1 \%{ }^{3}$ In a study done by Nabipour et $\mathrm{al}^{6}$ normal appendix was seen in $34.2 \%$. In another study done by Khan et al normal appendix were seen in $11.5 \%$ cases. $^{8}$ Ojo et al showed $11.7 \%$ cases of normal appendix. $^{10} \quad 17.8 \%$ and $20 \%$ cases of normal appendix was seen in a study done by Hobler et al and Morrison et al respectively. ${ }^{9,11}$

Mucocele of the appendix is the descriptive term for an appendix distended by mucus secondary to mucinous cystadenoma or mucinous cystadenocarcinoma. It can also occur due to occlusion of lumen by endometriosis or carcinoid tumor. ${ }^{20}$ However in our study, there was no such pathology and it was diagnosed as a simple appendiceal mucocele $(0.3 \%)$. Khan et al showed $0.06 \%$ cases of mucocele of appendix in his study. ${ }^{8}$

Carcinoids are the commonest tumor of the appendix. Our study showed $0.3 \%$ of the case which was diagnosed by histopathological examination (fig.1), the size of the tumor being less than $1 \mathrm{~cm}(0.6 \mathrm{~cm})$. Khan et al showed $0.08 \%$ cases of carcinoid in his study. ${ }^{8}$ Makaju et al showed $0.19 \%$ cases of carcinoid in his study. ${ }^{14}$ Another series showed the rate of $0.95 \%$ and $1.05 \%$ of carcinoids respectively. ${ }^{10,21}$

\section{CONCLUSION}

The diagnosis of acute appendicitis is primarily established by the surgeon's evaluation based on clinical features and physical examination. But the causes of acute appendicitis vary. Hence all appendectomy specimens should be sent for routine histopathological examination in order to determine the surgeon's rate of negative appendectomy with clinical correlation and to determine the etiological factors.

\section{REFRENCES}

1. Kim-Choy $\mathrm{Ng}$, Shih-Wei L. Clinical analysis of the related factors in acute appendicitis. Yale J bio med 2002;75:41-5.

2. Duzgan AP, Moram M, Uzun S et al. Unusual findings in appendectomy specimens: Evaluation of 2458 cases and review of the literature Indian J Surg 2004;66:221-6.

3. Edino ST, Mohammed AZ, Ochicha O, Anumah M. Appendicitis in Kano, Nigeria: a 5 year review of pattern, morbidity and mortality. Ann Afr Med 2004;3:38-41.

4. Ngodngamthaweesuk N, Tunthangtham A, Sakonya D. Acute Appendicitis: a 5-year review of histopathology and clinical presentation. The Thai Journal of Surgery 2003; 24:81-4.

5. Abu- Eshy SA, Ibn Ouf MA, Malatani TS et al. Acute appendicitis in females- a clinical study of 366 cases. Afr J med sci1995;24:227-30.

6. Nabipour F. Histopathological feature of acute appendicitis in Kerman Iran from 1997 to 2003. Am J Environ Sci 2005;1:130-2.

7. Chang SKY, Chan P. Recurrent appendicitis as a cause of recurrent right iliac fossa pain. Singapore Med J 2004;45:6-8.

8. Khan G, Grillo IA, Abu-Eshy SA, Khan AR, Mubarak J, Jastaniah S. Pathology of the appendix. J Natl Med Assoc. 2000;92:533-5.

9. Hobler KE. Acute and suppurative appendicitis: disease duration and its implications for quality improvement. Permanente journal spring 1998;2:5-8.

10. Ojo OS, Udeh SC, Odesanmi Wo. Review of the histopathological findings in appendices removed for acute appendicitis in Nigerians. J R Coll Surg Edinb 1991;36:245-8.

11. Morrison CA, Greco DL, Torrengton KG. Patterns of appendicitis at forward deployed United State army hospital: The Korean experience. Curr Surg 2000;57:603-9.

12. Temple CL,Hucherfort SH, Temple WJ. The natural history of appendicitis in adults- a prospective study. Ann Surg 1995;221:27881.

13. Dian A, Ali A, Azam UF, Khan MM. Perforated appendix-our local experience. Rawal Med J 2011;36:97-9.

14. Makaju R, Mohammad A, Shakya A. Acute appendicitis: analysis of 518 histopathologically diagnosed cases at the Kathmandu university Hospital, Nepal. KUMJ 2010;8:227-30.

15. Al- Samarrai a. Surgery for appendicular mass. Saudi J Gastroenterol 1995;1:43-6.

16. Domínguez JA, Planchar RM, Rocabert JI, Ortiz PL, Gil AC. Medical and/or surgical treatment of appendicular mass and appendicular abscess in children. Cir Pediat 2008;21:43-5

17. Barber MD; McLaren J; Rainey JB. Recurrent appendicitis. Br J Surg 1997;84:110-12. 
18. Malloy HR, Jason RS, Drew CR. The role of lymphoid hyperplasia in acute appendicitis. The Am J Surg 1945;67:81-6.

19. Nathans AA, Merenstein H, Brown SS. Lymphoid hyperplasia of the appendix. Pediatrics 1953;12:516-24.
20. Yakan S, Caliskan C, Uguz A, Korkut MA, Coker A. A retrospective study on mucocele of the appendix presented with acute abdomen or acute appendicitis. Hong Kong j.emerg. med. 2011;18:144-9.

21. Jones AE, Phillips Aw, Jarvis JR, Sargen K. The value of routine histopathological examination of appendicectomy specimens. BMC Surgery 2007;7:17. 